\title{
CINE, ÉTICA Y ALTERIDAD. METÁFORAS DEL ENCUENTRO CON EL OTRO
}

\author{
FILM, ETHICS AND ALTERITY. \\ METAPHORS OF ENCOUNTER WITH THE OTHER \\ Íñigo MARZÁBAL ALBAINA \\ Universidad del País Vasco / Euskal Herriko Unibertsitatea \\ inigo.marzabal@ehu.eus
}

\begin{abstract}
Resumen: El título del artículo me va a permitir un juego combinatorio tomando sus términos por parejas. De tal manera que lo que viene a continuación constará de tres partes. Una primera sobre la relación entre el cine y la ética; una última, en torno al cine y la alteridad. Y, entre ambas, un breve exordio que, siguiendo el pensamiento de Emmanuel Lévinas, reflexiona sobre el vínculo entre la ética y la alteridad. Para ello me valdré del análisis de tres películas: El lector (Stephen Daldry, 2008), Rosetta (Jean-Pierre y Luc Dardenne, 1999) y Lone Star (John Sayles, 1996).
\end{abstract}

Palabras clave: Arte. Cine. Ética. Alteridad.

\begin{abstract}
The article title will allow me a combinatorial game matching its terms in pairs. Thereby, what comes next will consist of three parts. The first one will address the relationship between cinema and ethics, while the last one will approach cinema and the otherness. In between both, there will be a brief exordium that, following the thought of Emmanuel Lévinas, reflects on the link between ethics and the otherness. All of this will be based on the analysis of three films: The Reader (Stephen Daldry, 2008), Rosetta (Jean-Pierre and Luc Dardenne, 1999) and Lone Star (John Sayles, 1996).
\end{abstract}

Key Words: Art. Film. Ethics. Otherness. 


\section{CINE Y ÉTICA: LA PERCEPCIÓN DEL OTRO}

La relación entre el arte ${ }^{1}$ y la ética se ha desarrollado en los últimos dos milenios en torno a un amplio movimiento pendular. En un extremo, un moralismo primero que supedita el arte a los criterios morales vigentes en la época en la que la obra es evaluada. Cuántos siglos de arte al servicio de mecenas regios y papales, de obras destruidas y prohibidas, de artistas juzgados y condenados. En el otro extremo, y a partir eminentemente del Romanticismo, el autonomismo, la autonomización de cada una de esas esferas. Es el momento de la reivindicación del arte por el arte. Es decir, el arte sólo es juzgable en términos artísticos y, por lo tanto, se encuentra fuera del ámbito de la ley y de la moral. Pero como en todo movimiento pendular cabe observar, puede ya apreciarse una tendencia del eje a desplazarse hacia el centro, una postura intermedia ${ }^{2}$ que, aceptando que toda expresión artística es un artefacto lingüístico, no puede negar el papel que el arte puede tener en el campo de la verdad y de los valores. Ahora bien, ¿cuál es ese papel? Si estuviésemos en una situación de monismo moral donde todos aceptásemos una única concepción del bien y de lo bueno, de en qué consiste una vida feliz y una sociedad justa, su papel sería evidente. Se trataría de adoctrinar al educando. Si hablásemos de cine, se trataría de proponer modelos de vida buenos, satisfactorios, edificantes; de poner en escena personajes sin tacha, unívocos, de una sola pieza; de mostrarnos el camino hacia el bien, la senda recta, el proceder exacto. Es decir, vuelta a la supeditación. Estando como estamos inmersos en una situación de pluralismo donde confluyen, conviven e, incluso, compiten diversas concepciones de bondad, felicidad y justicia, ¿cuál es el papel del arte en general, y del cine en particular, en el ámbito de la reflexión moral si ya no se trata de que una obra nos dicte las normas de cómo actuar moralmente? ¿Ni qué debo hacer ni cómo he de vivir? Vamos a verlo a partir de la película El lector (The Reader, 2008) del director británico Stephen Daldry.

Adaptación de la novela homónima de Bernhard Schlink, la película sitúa su historia en Alemania Occidental tras la Segunda Guerra

\footnotetext{
${ }^{1}$ Sin entrar en la estéril discusión sobre si el cine es un arte industrialmente realizado o una industria que, ocasionalmente, da a luz alguna obra de arte, a partir de aquí se considerará el cine dentro de las manifestaciones artísticas.

${ }^{2}$ Es lo que Noël Carroll (2000) denomina "autonomismo moderado".
} 
Mundial. Michael, un joven de 15 años, conoce azarosamente a Hanna, una revisora de tranvías que le dobla la edad y con la que comienza una relación sentimental. La trascendencia que el relato concede al hecho de narrar es evidente. El propio título de la película nos advierte de ello ${ }^{3} \mathrm{y}$, no en vano, se inicia con la rememoración de un ya maduro Michael sobre aquellos acontecimientos de su adolescencia y juventud que marcaron su vida y finaliza con esa misma historia, de la que hemos sido espectadores, relatada a su hija con la que ha mantenido una distante y tensa relación. Entre esos dos momentos, habrá un libro inculpatorio, un informe condenatorio o un personaje que aprende a leer. Y, por supuesto, el ritual que antecede a todo encuentro sexual entre la mujer y el joven: ella lo baña con agua, él la baña con palabras, porque, sistemáticamente antes de acostarse, debe leerle el fragmento de algún libro. Ella se niega obstinadamente a hablar de su pasado, le molesta su propia historia, pero anhela las historias de los demás. ¿Por qué, entonces, narrar?

Podríamos partir de la famosa afirmación de Roland Barthes, en su no menos famosa Introducción al análisis estructural de los relatos, en la que afirma que "no hay ni ha habido jamás en parte alguna un pueblo sin relatos" (1970: 9). Efectivamente, no existe civilización alguna conocida que no posea sus propias narraciones. Toda colectividad de la que se tiene noticia ha sido capaz de dotarse de historias en las que reconocerse. Toda una constante antropológica: la actividad de relatar historias y de participar vicariamente de lo relatado. Así, la historia de la humanidad es, también, la Historia de sus historias. Un modo de explicarse a sí misma, entender lo que le rodea y dar sentido a su existencia. Porque una narración no es un mero agregado, más o menos azaroso, de acontecimientos. Contar implica, por una parte, relatar, narrar; por otra, enumerar, dotar de un orden a una serie dada de elementos. Ambos significados se aúnan en la narración. Planteamiento, nudo y desenlace; núcleos y catálisis; peripecias y anagnórisis; causalidad y lógica narrativa. Todo un complejo entramado destinado a dar sentido a lo que se relata.

Un día Hanna desaparece sin previo aviso. Años después, siendo Michael estudiante de derecho acude a la sala de un tribunal donde seis mujeres, antiguas guardianas de un campo de concentración, son juzgadas

${ }^{3}$ De hecho, la traducción del título original de la novela en la que se basa, Der Vorleser, sería: El que lee en voz alta. 
por haber dejado morir a trescientas presas en el incendio de una iglesia. Una de ellas es su antigua amante. Michael asiste atónito al devenir del juicio. En el interrogatorio al que se la somete, Hanna se enfrenta vehementemente al tribunal. No entiende por qué se la juzga, no entiende de qué se la acusa. Si no dejó salir a aquellas mujeres de la iglesia en llamas fue porque su deber era, precisamente, impedirlo. Ella, que nunca cuestionó las órdenes que recibía, parece no darse cuenta de lo que está en juego, parece no saber leer ni la gravedad de sus actos ni la situación en la que se encuentra. Y no utilizo el verbo leer casualmente. Resulta que Hanna, efectivamente, no sabe leer. Es analfabeta. En un momento del juicio, surge una prueba encausatoria determinante: un informe firmado que da cuenta de aquél terrible acto. El resto de las acusadas la señalan como firmante del escrito. Ella, al principio, lo niega. Pero cuando deba realizar una prueba caligráfica para comparar la firma, se niega y asume la autoría del informe. Sus compañeras serán condenadas a 4 años de cárcel. Ella a cadena perpetua. Ha preferido asumir la vergüenza de la autoría de aquel execrable crimen a la vergüenza de mostrar públicamente que es analfabeta.

A partir de aquí pueden establecerse una serie de cuestiones sobre las que merece la pena detenerse, aunque sea brevemente. En primer lugar, la culpa, la culpabilidad. Doble culpabilidad. La jurídica, que hace referencia a Hanna, tal vez no como última responsable de aquellas muertes, pero sí como cómplice en ellas. Pero hay otra culpa que es la que interesa tanto al autor del libro como al de la película. La culpa moral de la siguiente generación a la participante en el genocidio judío, singularizada aquí en Michael. El joven, al amar a Hanna, se siente, de alguna forma, culpable de aquellos asesinatos. ¿Es posible amar a un monstruo? Y, si es así, ¿hasta qué punto se es cómplice de los mismos? ¿Dónde situarnos moralmente ante nuestros padres, abuelos o vecinos, a los que queremos, admiramos y respetamos, sabiendo que, por acción u omisión, participaron en aquella monstruosidad?

En segundo término, y junto a la culpa, la cuestión del analfabetismo. Pues el lingüístico no deja de ser un trasunto del moral. Hanna es una analfabeta moral. De ahí que no quepa sino acudir a otra Hanna, a Hannah Arendt y a su banalidad del mal. El mal no como algo propio de criaturas extraordinarias, de mentes perversas, sino como algo en lo que cualquiera puede incurrir. Cualquiera que se niegue a pensar por 
sí mismo, que se limite a hacer lo que se le ordena sin pararse a reflexionar sobre los fundamentos y consecuencias de su actuar. Eichmann ${ }^{4}$ encarnaba esa ausencia de pensamiento, la obediencia ciega, la incapacidad de pensar autónomamente sobre los motivos y resultados de las propias acciones.

Por supuesto, el planteamiento tanto de la novela como de la película ha sido duramente criticado. El argumento recurrente puede formularse así: al focalizar el relato en el victimario, en el verdugo; al dar a conocer sus razones y circunstancias, ambos textos empujan al lector/ espectador a identificarnos e, incluso, a empatizar con él. Dicho de manera rápida: novela y película humanizan al monstruo. Pues bien, aquello que se considera como moralmente execrable, parece que es lo moralmente exigible.

Milan Kundera lo escribió ya hace unos años. La única función moral de la literatura es la de hacernos descubrir y percibir facetas y aspectos de la existencia humana hasta entonces desconocidos (2000: 11-30). Incluso de los monstruos. El arte narrativo, en lo que tiene de singularizar, de individualizar, dar cuerpo al principio, la idea, el arquetipo, nos puede ayudar a ser más receptivos a esas razones, puede contribuir a "ampliar el horizonte del nosotros" (Rorty: 1991: 214). Hanna va a ser condenada a cadena perpetua y en la cárcel va a aprender a leer. Y va a leer, por supuesto a Hanna Arendt, pero también a Primo Levi, Elie Wiesel, Tadeusz Borowski o Jean Améry: "la literatura de las víctimas" (Schlink, 2000: 191). Se va a alfabetizar, lingüística y moralmente. Será a través de los escritos de los supervivientes como pueda imaginarse, pensarse, reconocerse por fin, como parte de esa trama monstruosa. Será capaz de, en este caso a través de la literatura, de percibir lo humano en el otro deshumanizado y de monstruo en ella misma. De manera que, tras veinte años de cárcel, le será conmutada la pena. La víspera de salir a la calle, consciente ahora del mal realizado, de la imperdonable iniquidad de su acción, encaramada a los libros que le han abierto los ojos a los otros, se suicidará.

En su contacto con el arte, en este caso con la literatura, Hanna se transforma. Hans-Georg Gadamer, una de las figuras señeras de la hermenéutica, distinguía, por decirlo apresuradamente, entre dos tipos de ciencias: las positivas y las del espíritu. En las primeras, el concepto

${ }^{4}$ A este respecto, véase Arendt (1999). 
de verdad que rige es el de adecuación, el de correspondencia entre el enunciado y la cosa que designa; en las segundas, por el contrario, la verdad se ve como apertura. O utilizando otro concepto clásico que el pensamiento hermenéutico rehabilita, en las ciencias del espíritu la verdad se concibe como aletheia (Gadamer, 1992: 53), como desvelamiento, como desocultamiento. Frente al arte por el arte, es decir, la experiencia artística totalmente desvinculada del ámbito de la verdad, de los valores morales o de la existencia en sociedad, Gadamer reivindica la experiencia estética como verdadera experiencia. ¿Por qué? Porque transforma a quien la tiene. Porque allí donde antes no había nada, ahora hay algo. Algo se ha desvelado.

\section{EXORDIO: ÉTICA Y ALTERIDAD}

Umberto Eco, en la discusión epistolar que mantiene con el cardenal Martini acerca de la posibilidad de una ética laica, y recogida en su libro Cinco escritos morales, afirma: "La ética empieza cuando entra en escena el otro" (2010: 103). Pues bien, la formulación más acabada de una ética fundamentada en el otro, en la alteridad, corresponde, sin duda a Emmanuel Lévinas. Frente a la ética de raigambre kantiana que es a priori (no enturbiada por ninguna experiencia sensible), categórica (incondicionada, no condicionada por nada externo a uno mismo) y autónoma (en tanto que es la que el sujeto se impone racionalmente a sí mismo), Lévinas reivindica el encuentro con el otro, con el rostro del otro como el verdadero y primordial acontecimiento ético. El rostro del otro como una "epifanía" moral (2002: 98). La gran pregunta ética "¿Qué debo hacer?" no es, según este filósofo, la que un sujeto libre y autónomo se hace a sí mismo. La ética no comienza como una pregunta, sino como una respuesta. Una respuesta a la demanda del otro, de algo externo a uno mismo, de algo heterónomo. Yo soy responsable del otro, incluso a mi pesar (Lévinas, 2002: 102). Lévinas (1976) escribió profusamente sobre la poesía de Paul Celan y utilizaba a menudo esos versos suyos que vienen a decir: "Soy yo, cuando primero soy tú" (1987: 163). Es decir, el yo no es cuidado de sí. En una relación ética, el yo es, primera y primordialmente, cuidado del otro.

Pues bien, si hay algún cine en el que la huella de Lévinas es patente, ese es, sin duda, el cine de los hermanos Jean-Pierre y Luc Dardenne. Luc, 
que estudió filosofía con un discípulo de Lévinas, publicó en el año 2006 una especie de cuaderno, de diario de trabajo, titulado Detrás de nuestras imágenes. En la entrada correspondiente al 19 de enero de 1996, en pleno rodaje de La promesa (La promesse, 1996), escribe: "Emmanuel Lévinas ha muerto durante nuestro rodaje. La película le debe mucho a la lectura de sus libros. A su interpretación del cara a cara, del rostro como primer discurso" (2006: 54). La promesa, así como el resto de su filmografía. La clave de bóveda del edificio teórico que levanta el filósofo de origen lituano es, sin duda, la noción de rostro. Que no es la cara. En el verdadero encuentro con el rostro del otro, escribirá, se olvida el color de sus ojos (1991: 79). El rostro es una metáfora. El rostro es lo que habitualmente permanece desnudo, expuesto, desprotegido. Vulnerable. De ahí que en sus escritos establezca cuatro grandes tipos de otros, desnudos, expuestos, desprotegidos y vulnerables: el extranjero inmigrante, el pobre, el huérfano y la viuda. Figuras que se corresponden, casi literalmente, con cuatro películas de los Dardenne: la inmigración en La promesa (1996), la pobreza en Rosetta (Rosetta, 1999), la orfandad en El hijo (Le fils, 2002), la viudedad, en fin, en El silencio de Lorna (Le silence de Lorna, 2008).

Vamos con ese otro que es el o la pobre. El socialmente excluido.

\section{CINE Y ALTERIDAD: UNA REFLEXIÓN MORAL}

La película Rosetta se desarrolla en Seraing, ciudad del norte de Bélgica, cercana a Lieja. Hace unos años, importante núcleo siderúrgico, en el presente del relato, asolada por el paro. Rosetta es una joven de 17 años despedida sistemáticamente de los precarios trabajos que logra encontrar. Padre ausente, vive con su madre alcohólica, que se prostituye ocasionalmente para conseguir un trago, en una caravana en un camping situado en las afueras de la ciudad. Cuando no tiene trabajo, Rosetta y su madre sobreviven con la venta de ropa a tiendas de segunda mano y lo que la joven consigue pescar furtivamente en un río cercano al camping. Viven en la periferia de la periferia.

Que todas las historias de los Dardenne se desarrollen en este contexto socioeconómico de crisis es importante, pero no determinante. En la entrada del diario correspondiente al 11 de mayo del 1997, Luc vuelve a citar a Lévinas: "La vida espiritual es esencialmente vida moral y su lugar predilecto es el económico" (2006: 69). Pero, más allá de la precaria 
situación socioeconómica en la que esos personajes están inscritos, lo que interesa señalar a los Dardenne es la idea, muy lévinasiana por otra parte, de que todos ellos son libres para elegir. Todos los protagonistas de sus historias se ven impelidos a tomar una decisión. Más allá de la circunstancia material de la que parten, serán obligados a retratarse moralmente a través de las decisiones que adoptan.

Lo que hace interesante a la película que nos ocupa, es el modo como está filmada. La cámara al hombro, pegada a su cogote, sigue obsesiva y tenazmente las evoluciones del personaje. Ella ocupa la centralidad. Nadie más tiene cabida en ese encuadre si no es a la fuerza. Por supuesto, esta forma de filmar a Rosetta tiene diversas implicaciones semánticas. Subrayo cuatro.

Por una parte, los Dardenne conciben a la joven como una guerri1lera. Es una película de "guerra", escribirá Luc (2006: 63). La misma violencia, perseverancia, tenacidad de la cámara es la de Rosetta en la guerra sin cuartel contra ese enemigo invisible que es el paro. La búsqueda de trabajo como una guerra de trincheras.

En segundo término, este encuadre cerrado sobre personaje lo extrae de su contexto, lo abstrae del decorado y de su circunstancia concreta. $\mathrm{Y}$ es que el cine de los Dardenne no es un cine de contexto y circunstancia. Es un cine de cuerpo y gesto. De rostro. Luc plasma en su diario un pasaje del Macbeth de Shakespeare: "No existe arte que pueda descifrar el sentido del alma en las líneas del rostro" (2006: 76). Contrariamente, ese es el desafío en el que se empeñan: "descifrar las maquinaciones del alma, escribirá Luc, filmando el rostro" . Filmar el rostro, siguiendo una vez más a Lévinas, como primera palabra. Hacer hablar al rostro.

En tercer lugar, este encuadre centrado en el cogote de Rosetta señala un amplio fuera de campo, nos habla de la gran pregunta que atraviesa todo su cine. Luc: “¿Qué significa ser humano hoy?” (2006: 108). Es decir, el ser humano como enigma, como ecuación a despejar. Repleto de inters-

\footnotetext{
${ }^{5}$ Sin duda hay un fuerte vínculo entre esta idea de expresar la evolución y transformación de la interioridad humana a través del gesto del rostro y aquélla, bressoniana, de representar lo mismo mediante los avatares de las manos, presentes en Pickpocket (Pickpocket, 1959) o Un condenado a muerte se ha escapado (Un condamné à mort s'est échappé ou Le vent souffle où il veut, 1956). Del mismo modo que los aforismos del diario de Lucno dejan de recordarnos a los del libro de Robert Bresson, Notas sobre el cinematógrafo.
} 
ticios, de sombras, de zonas opacas. Como ese fuera de campo que apenas se sugiere, que sólo se entrevé. De ahí la invitación que Luc nos expresa para adentrarnos en el personaje "como un coche se adentra en la noche" (2006: 125). En el prefacio a su obra magna, Totalidad e infinito, Lévinas escribe: "La ética es una óptica" (2002: 55). Qué mejor medio de expresión que el cine para intentar plasmar el apotegma. ¿En qué consiste esa mirada ética? Que en términos cinematográficos es lo mismo que decir: ¿dónde colocar la cámara? En la entrada correspondiente al 2 de diciembre de 1995, Luc deja escrito: “¿Dónde colocar la cámara? Es decir: ¿Qué muestro? Es decir: ¿Qué escondo? Esconder es, sin duda, lo más esencial" (2006: 53).

Finalmente, esta forma de filmación tiene por objeto mostrar el estado de encapsulamiento de los personajes. Rosetta se nos presenta como presa de una obsesión. La joven concibe el trabajo como un modo de reafirmación personal. Tener un trabajo es para ella la única manera de ser, de no caer en el olvido, de no desaparecer, de tener un lugar en la sociedad. Es decir, Rosetta está obsesionada con conseguir un trabajo. De ahí ese encuadre que la aprisiona, la encierra, la aísla, la encapsula, la enclaustra. No ve más allá de su obsesión. No ve más allá del encuadre. Y es que todo estás pensado para retardar el encuentro con el otro. Para permitir que el otro penetre en el encuadre. Para llegar, por fin, al cara a cara.

Tras tanta agitación, ese encuentro requiere de la detención. Tras tanto movimiento espasmódico es preciso detenerse, alzar la vista y mirar al fuera de campo. Es el momento de la redención. Rosetta decide finalizar con su sufrimiento y el de su madre abriendo la espita del gas de la caravana. Pero el gas se ha acabado y debe ir a la recepción del camping a por una bombona llena. Y es en ese último plano de regreso a la caravana del que da cuenta el relato donde se nos resume, metafóricamente, la peripecia vital de la joven. Metafórico porque ese trayecto no deja de ser trasunto de ese otro más amplio que nos ha mostrado la película. Rosetta acarreando una pesada carga, rechazando vehementemente la ayuda de los demás, hasta caer exhausta y desesperada. No obstante, puede afirmarse que el final es esperanzador. Por primera vez en el film, la joven, ciega al otro, a los otros, durante todo el metraje, ensimismada, levanta la vista y, por fin, serena, ve a Riquetmás allá de los límites del encuadre. El único personaje que verdaderamente se ha interesado por ella, pero al que no ha dudado en denunciar para quedarse con su trabajo. 
Así es como el repliegue sobre uno mismo nos incapacita a menudo para comunicarnos con el otro. De ahí la pertinencia de acudir a ese relato y metáfora, a la vez, que da cuenta de esta época en la que nos ha tocado vivir conjugada en torno a términos como pluralismo, inconmensurabilidad o multiculturalidad. Periodo en el que diversos criterios morales compiten entre sí, cuando no coexisten sumidos en la mutua indiferencia. Una situación histórica en la que nada parece poder probar que una norma pueda ser universalmente válida para todos los seres humanos y superior a las otras. Me estoy refiriendo a la Torre de Babel. Relato, por una parte, de la desmesura humana, del desafío humano al orden divino y su consiguiente castigo: la confusión de lenguas, la radical incomunicación entre los diferentes grupos que pueblan la tierra. Metáfora, por otra parte, de la dificultad para hacer inteligibles formas de vida distintas a la nuestra. Pero allí donde tradicionalmente no ha sido vista sino una maldición, surge, ahora, el significado positivo de la metáfora: la inexistencia de un único código lingüístico, la diversificación de las lenguas, amplía las posibilidades de pensar el mundo y a nosotros y a los otros en él. Y es que cada lengua, como afirma George Steiner en su elogio de Babel, posee su propia "gramática de la esperanza" (1992: 74)6. Dicho en otros términos, y acercando el ascua al fuego de la ética, la inexistencia de un monismo moral, de una única concepción sobre el bien y lo bueno, nos obligan a situarnos en otro lugar desde el que lo múltiple, lo complejo y lo heterogéneo deben tener cabida.

La historia que relata Lone Star (John Sayles, 1996) ${ }^{7}$ se desarrolla en una pequeña ciudad tejana que constituye todo un crisol de culturas, una Babel de etnias, de ámbitos culturales y comunidades lingüísticas diferentes, que conviven de manera más o menos civilizada. La ciudad se llama, tal vez de manera excesivamente didáctica, Frontera. Y es que los problemas que aquejan a Frontera son, precisamente, problemas fronterizos. Pero no sólo fronteras geopolíticas (EE. UU. / México). También fronteras generacionales (padres / hijos), raciales y étnicas (blancos / mexicanos / negros / indios), morales (ley / justicia) y temporales (pasado / presente). La historia se inicia en el desierto cuando es descubierto un cadáver. Y no

\footnotetext{
${ }^{6}$ Otra obra de este mismo autor tiene el significativo título de Después de Babel: aspectos del lenguaje y la traducción.

${ }^{7}$ Para un análisis más extenso y pormenorizado de la película, puede consultarse Marzábal (2004).
} 
es casual que una película articulada sobre la frontera, sobre la diferencia, se inicie en lo indiferente. Pues eso es el desierto, un espacio sin límites, propiciador de trayectos circulares, un espacio, en definitiva, liberado del tiempo. Espacio mítico, por lo tanto, en lo que tiene de convocatoria al imaginario colectivo del espectador: el western; y espacio del mito también, pues allí emerge el cadáver, el espectro, el fantasma del otrora sanguinario sheriff Charlie Wade. De manera que el acto de exhumar, de desenterrar, de sacar a la luz el cadáver y determinar su identidad es el mismo que corresponde al resto de los personajes que deben exhumar, desenterrar, sacar a la luz su pasado para mejor exorcizarlo y determinar su lugar en el mundo. Dicho de otra manera, la investigación que se emprenderá para establecer quién es el muerto y quién lo mató constituye el verdadero mcguffin de la película, la excusa para propiciar que se entrecrucen toda una serie de historias pasadas y presentes. De entre todas ellas, destaco una: la del sheriff Sam Deeds, encargado de aclarar los hechos, y la de Pilar Cruz, profesora de Historia de la escuela pública de Frontera. Sam y Pilar fueron novios en la adolescencia, pero la oposición de sus respectivas familias impidió que su amor fructificase.

De tal manera que lo que la película plantea es una doble reescritura de la historia: de la historia personal y de la colectiva. Personal, porque Sam y Pilar operan en el presente a partir del conocimiento, limitado conocimiento, que tienen del pasado. De ahí la necesidad de bucear en su historia. O mejor, en esa parte fundamental de su historia que son sus respectivos padres. Y paralelamente a esa actividad de exorcización individual, reescritura de la Historia colectiva. Es eso lo que se discute en la reunión de la escuela en la que Pilar es, nada casualmente, profesora de Historia. La cuestión de la que se trata allí es la de determinar en base a qué se trazan esas líneas imaginarias que son las fronteras. La ahora minoría blanca pretende utilizar una visión monolítica de la Historia al sentir amenazados sus privilegios. Pero la narración única sobre el pasado ya no basta. De ahí que Pilar utilice en sus clases el "perspectivismo". Sus palabras a la Junta escolar serán: "Sólo intentaba dar una explicación de la complejidad de nuestra situación".

La coherencia de Lone Star es cómo esa necesidad de multiplicar las perspectivas y ceder la palabra a los otros, antes ominosos y ahora problematizados, tiene reflejo en su peculiar estructura narrativa. Frente a los relatos de la época de las certidumbres (continuos, causales, unívocos y 
cerrados), la película está organizada en torno a una focalización variable en la que representantes de los diferentes grupos étnicos y sociales toman la palabra en pie de igualdad. Es decir, una estructura discontinua, fragmentada, múltiple y abierta. Frontera constituye, si se prefiere una denominación más al uso, una sociedad multicultural en la que diversos grupos reclaman para sí el respeto a su propia especificidad, la necesidad de límites precisos en torno a los que poder definir un nosotros irreductiblemente diferente al ellos. Pero lo que la hace interesante es que, una vez que ha establecido estas barreras, se dedique a demolerlas o, por lo menos, a mostrarnos su permeabilidad. Todas menos una.

$\mathrm{Y}$ es que en el film hay otra aparente frontera que recubre las demás. $\mathrm{Y}$ digo aparente porque su tratamiento es justamente inverso al resto. Es la frontera entre pasado y presente. Si las anteriores se caracterizaban por su arbitrariedad y se planteaba, en consecuencia, la necesidad de transcenderlas, con respecto al límite temporal, Lone Star expresa su inexistencia y, en buena lógica, la necesidad de fijar ese límite. El pasado irrumpe en forma de analepsis. Siete concretamente. Lo que en este punto me interesa destacar es cómo está expresado formalmente ese ir y venir constante entre pasado y presente: ya sea al inicio y/o al final del flashback, un suave y lento movimiento de cámara nos traslada, en continuidad, de una a otra coordenada temporal. Es decir, presente y pasado conviven en el mismo, y nunca mejor dicho, plano. ¿Cómo interpretar esta filigrana temporal al hilo de lo que aquí se está discutiendo? Como la pervivencia del antes en el ahora, como el peso del ayer en el hoy, como la inexistencia de fronteras entre lo que fue y lo que es. En definitiva: de cómo el pasado determina y condiciona el presente.

Así las cosas, ¿cuál es la propuesta de Lone Star? En un principio, y por lo dicho más arriba, parece desprenderse que aboga por ese pleonasmo que es el mestizaje cultural. Así lo atestiguarían las parejas mixtas que se crean, el museo de los Indios Negros Semínolas o la propia banda sonora del film que mezcla diferentes registros musicales. Pero la película va un poco más allá. Para expresar esta idea acudo a la potente metáfora con la que finaliza la narración. Hay un único flashback en el que entramos y salimos de él por corte neto. Es el relativo al final de la relación entre unos jóvenes Sam y Pilar. Si en los anteriores era preciso establecer una frontera entre el pasado y el presente, aquí es necesario, una vez más, derribarla. Dar continuidad a la relación. Un problema: Sam y Pilar se 
saben ya hijos de un mismo padre. Habiendo accedido a las verdaderas razones por las que fueron separados, consanguíneas y no raciales, deciden permanecer juntos, mantener una relación incestuosa. ¿Cómo interpretar esto? Por supuesto, no como forma de transgredir ese tabú fundacional de la civilización que atribuimos al incesto; tampoco sólo como expresión de la justeza de sus sentimientos frente a la arbitrariedad y convencionalidad de las barreras legales y sociales. El incesto como solución de futuro. Pues si el mestizaje implica una mezcla entre diferentes, el incesto lo es entre iguales, lo es entre hermanos. Más allá de lo diferencial, del carácter distintivo, del rasgo intraducible, de la inconmensurabilidad cultural, Lone Star reivindica lo común: el pasado compartido. Pilar y Sam sellan su incierto futuro en el mismo lugar en el que se truncó su relación veintitrés años atrás: en el Drive-In. Ahora espacio abandonado, abierto, sin límites. Regreso al desierto. Allí reactualizan su amor pese a las barreras de la sangre. Junto a Pilar y Sam, la blanca pantalla rasgada en la que antaño se proyectaban películas al aire libre. Pantalla que, pese a los desgarrones, a las cicatrices que el Tiempo ha inscrito en ella, ofrece la posibilidad de proyectar, en el doble sentido que admite el término, una historia todavía por hacer, todavía por determinar.

El filósofo Ernst Tugendhat finaliza una conferencia titulada significativamente "Identidad personal, particular y universal" con un cuento jasídico que dice así:

Un viejo rabino preguntó una vez a sus alumnos cómo se sabe la hora en que la noche termina y el día comienza. "Será", dijo uno de los alumnos, "cuando uno puede distinguir a lo lejos un perro de una oveja". "No", contestó el rabino. "Será”, dijo otro, "cuando puedo distinguir a lo lejos un almendro de un duraznero”. "Tampoco”, contestó el rabino. “¿Cómo lo sabremos entonces?", preguntaron los alumnos. "Lo sabremos”, dijo el rabino, "cuando, al mirar a cualquier rostro humano, reconozcas a tu hermano o a tu hermana. Mientras tanto, seguiremos estando en la noche (2002: 31).

\section{REFERENCIAS BIBLIOGRÁFICAS}

ARENDT, H. (1999). Eichmann en Jerusalén. Un estudio sobre la banalidad del mal. Barcelona: Lumen.

BARTHES, R. (1970). "Introducción al análisis estructural de los relatos". 
En Análisis estructural de relato, AA.VV, 9-43. Buenos Aires: Tiempo Contemporáneo.

CARROLL, N. (2000). "Art and Ethical Criticism: An Overview of Recent Directions of Research". Ethics 110.2, 350-387.

DARDENNE, L. (2006). Detrás de nuestras imágenes. Madrid: Plot Ediciones.

ECO, U. (2010). "Cuando entra en escena el otro". En Cinco escritos morales, 99-111. Barcelona: Debolsillo.

GADAMER, H.-G. (1992). “¿Qué es la verdad? (1957)”. En Verdad y Método II, 51-62. Salamanca: Ediciones Sígueme.

KUNDERA, M. (2000). "La desprestigiada herencia de Cervantes". En El arte de la novela, 11-30. Barcelona: Tusquets.

LÉVINAS, E. (1976). "Paul Celan. De l'être à l'autre". En Noms Propres, 49-56. Paris: Fata Morgana.

(1987). De otro modo que ser, o más allá de la esencia. Salamanca: Ediciones Sígueme.

(1991). Ética e infinito. Madrid: Visor Libros.

(2002). Totalidad e infinito: ensayo sobre la exterioridad. Salamanca:

Ediciones Sígueme.

MARZÁBAL, I. (2004). "Identidad y comunidad". En Deliberaciones poéticas. Cine y ética narrativa, 52-71. Bilbao: Servicio Editorial UPV / EHU.

RORTY, R. (1991). Contingencia, ironía y solidaridad. Barcelona: Paidós. SCHLINK, B. (2000). El lector. Barcelona: Anagrama.

STEINER G. (1992). Presencias reales. Barcelona: Destino. (2001). Después de Babel: aspectos del lenguaje y la traducción. Madrid: Fondo de Cultura Económica.

TUGENDHAT, E. (2002). "Identidad personal, particular y universal”. En Problemas, 15-31. Barcelona: Gedisa.

Recibido el 2 de marzo de 2020.

Aceptado el 15 de abril de 2020. 